\title{
Education in times of covid-19: are students learning in ergonomic conditions?
}

\author{
Maria-Elena Boatca $^{1 *}$, Diana Robescu ${ }^{1}$, Romulus Corlan $^{2}$ and Nicoleta Mirea ${ }^{1}$ \\ ${ }^{1}$ Politehnica University of Timisoara, Faculty of Management in Production and Transportation, \\ 14 Remus street, 300191 Timisoara, Romania \\ ${ }^{2}$ Politehnica University of Timisoara, Faculty of Electrical and Power Engineering, \\ 2 Vasile Parvan Blv., 300223, Timisoara, Romania
}

\begin{abstract}
For more than a year, the way people work and learn witnessed dramatic changes on the back of the Covid-19 pandemic. While workers were supported and provided with trainings and a variety of sources of information, students did not benefit from the same 'privilege'. In Romania, students had to adapt to online learning system since March 2020. To properly assess the impact of online learning on students' health (both physical and mental), the authors conducted a study on students at Politehnica University of Timisoara. As part of this study, subjects were assessed using 'Rapid Office Strain Assessment' (ROSA). While some of them learn in ergonomic conditions, there are others exposed to high postural risk (primarily generated by use of inappropriate furniture). This assessment is part of a larger ergonomic intervention focused on educating students on the importance of creating ergonomic conditions at home with the aim to improve quality of life.
\end{abstract}

\section{Introduction}

After a year since the Covid-19 outbreak, it has become clear for everyone that the way one learns and works suffered dramatic changes. Once regarded as a dream that might never come true, working from home proved more like a nightmare for majority of those compelled to work in remote arrangements for long periods (even for the whole 2020-2021 timeframe). However, trainings and informative materials on proper organisation of working space, risks, and importance of correct posture for office workers created the opportunity for reducing musculoskeletal disorders (MSDs) and improving the working space used in workers' dwellings.

However, students have been learning online during the past year and there is little literature and information dedicated to them that might help students reduce the risks they are exposed to. Their health and wellbeing are just as important as it is for employees, and, hence, should not be regarded differently. As part of a larger study at Politehnica University of Timisoara (Romania), focused on assessing conditions in which students learn and their

\footnotetext{
${ }^{*}$ Corresponding author: maria.boatca@student.upt.ro
} 
wellbeing since attending online classes exclusively, in this paper the authors present the assessment of students' learning space using Rapid Office Strain Assessment method (ROSA).

\section{ROSA method - literature review and methodology}

\subsection{Literature review}

Increasing number of office workers and rising use of visual display units (VDUs) generated a higher incidence of MSDs. Redivo et al. (20021) highlight the direct connection observed between poor office ergonomics and a high prevalence of MSDs [1].

In this context, renowned assessment methods (primarily designed for assessment of workplaces dedicated to blue-collar employees) may generate a lower risk than it is. The need for an assessment method dedicated to offices motivated a group of researchers to create ROSA method, which is a method aimed at evaluating compliance of offices design and organization with ergonomic requirements and standards. Jozwiak et al. (2019) demonstrated that ROSA is an easy-to-use instrument for assessment of computer workstations by correlating the results obtained from ROSA with RULA results [2].

ROSA has been successfully used for ergonomic assessment [3]. However, in many studies, ROSA was used alongside other assessment methods to generate comprehensive and reliable results. In the literature are described numerous studies that used ROSA in combination with other methods such as Quick Exposure Checklist, Nordic Questionnaire, and Cornell Musculoskeletal Discomfort Questionnaire to correlate results and obtain relevant conclusions of MSDs risks and areas of improvement [4-9].

At the same time, ROSA was used as starting point for development of frameworks and methods for prioritising ergonomic interventions. A representative example is the study of Delice et al., which proposed an approach for identifying departments and office components that generate higher strains [10].

Safarian et al. (2019) used ROSA for conceiving and assessing the outcome of two ergonomic interventions: one focused on educational aspects, and one focused on technical improvements. Comparison of ROSA scores indicated reduction of MSDs risk, demonstrating that ROSA is a reliable instrument for both diagnose and feedback [11].

In addition, other researchers also relied on ROSA to conceive education-based ergonomic interventions, highlighting again that ROSA is a highly reliable instrument [1214]. Another interesting observation comes from Matos et al. (2015) which support the idea that assessments performed with ROSA method may be more related to inappropriate use of desk, chair, and office equipment rather than poor ergonomics of the office [15].

\subsection{Methodology}

ROSA is a checklist based on observations, encompassing graphical representations of different postures and details specific to office workers [3]. CSA Z412 - the Canadian standard for office ergonomics - scientific literature on ergonomics and information from the Canadian Centre for Occupational Health and Safety website were the primary sources for creation of ROSA [3].

The checklist is split in three sections, each encompassing sub-sections as follows: section A - chair (sub-sections: chair height, pan depth, armrests, and back support), section $\mathrm{B}$ - monitor and telephone (sub-sections: monitor, telephone), section C - mouse and keyboard (sub-sections: mouse, keyboard) [3]. Figures 1 and 2 present the graphical representations of the postures analysed in each section. 


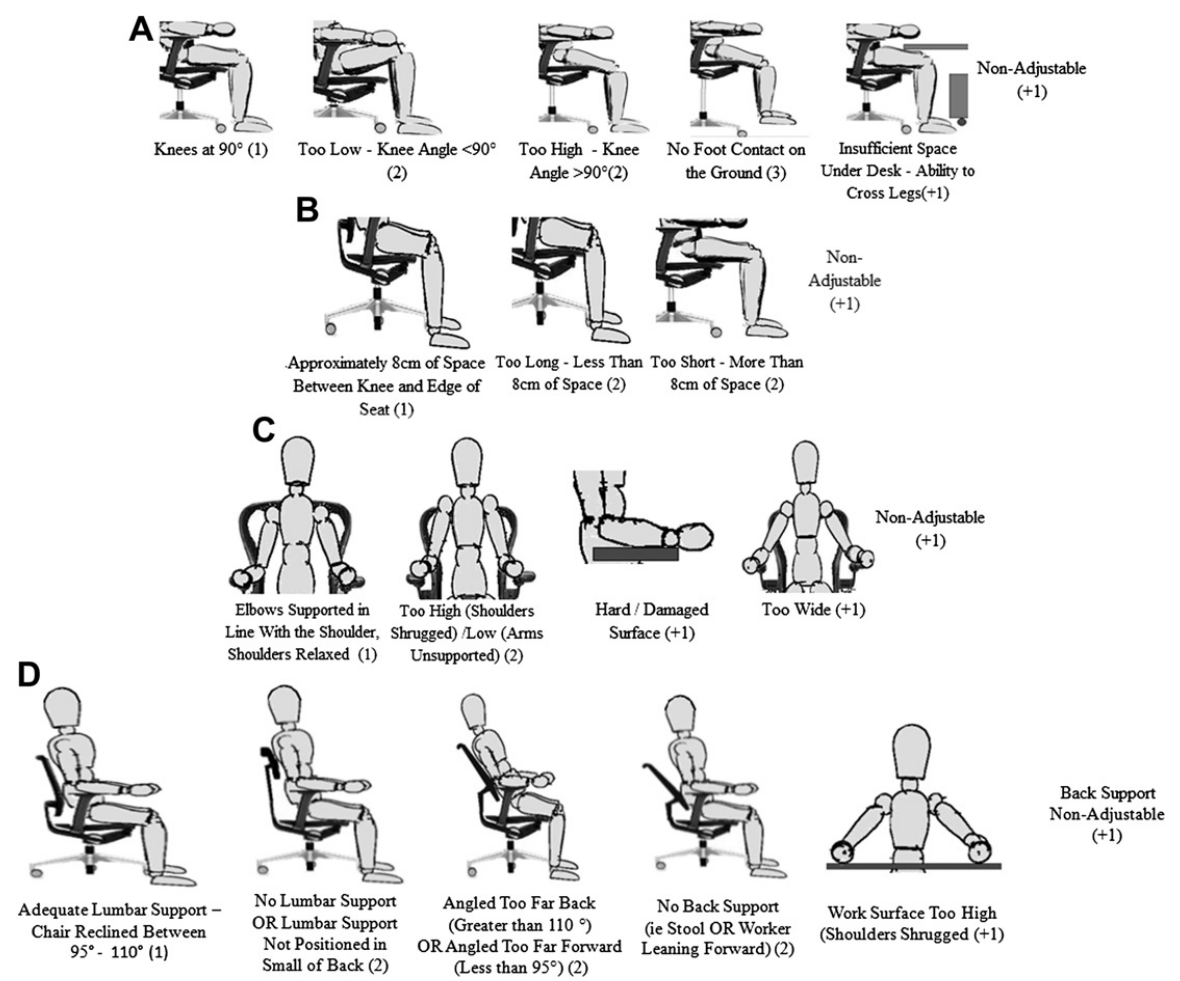

Fig. 1. Postures and scores referring to chairs in ROSA method [3].

The postures defined as neutral in the CSA standard were assigned a score of 1 (the minimum score that can be achieved in each ROSA sub-section). Further, for each subsection, scores of 1 to 3 correspond to various deviations from the neutral position, with potential addition of 1 point for certain details that may aggravate the situation (e.g., nonadjustable features of the chair, too high desk, duration of more than 1 hours continuously using the monitor, mouse, or keyboard). Total scores above 5 are considered concerning from an ergonomic perspective, requiring improvements to reduce risks.

Calculation of the score for each section is based on matrices included in the assessment form and presented in figure 3. Each sub-section has a score reflecting both the posture and additional factors adding to this score. Subsequently, the section score is the intersection of the sub-section scores in the corresponding matrix. As per figure 3, chair score is the intersection of armrest and back support, and seat pan height/depth scores, respectively. Similarly, section B score is the intersection of monitor and telephone scores, and section C score is the intersection of keyboard and mouse scores in their corresponding matrices. Section B and section C scores are used to create a fourth score, which is combined with the chair score to obtain the final ROSA score. 

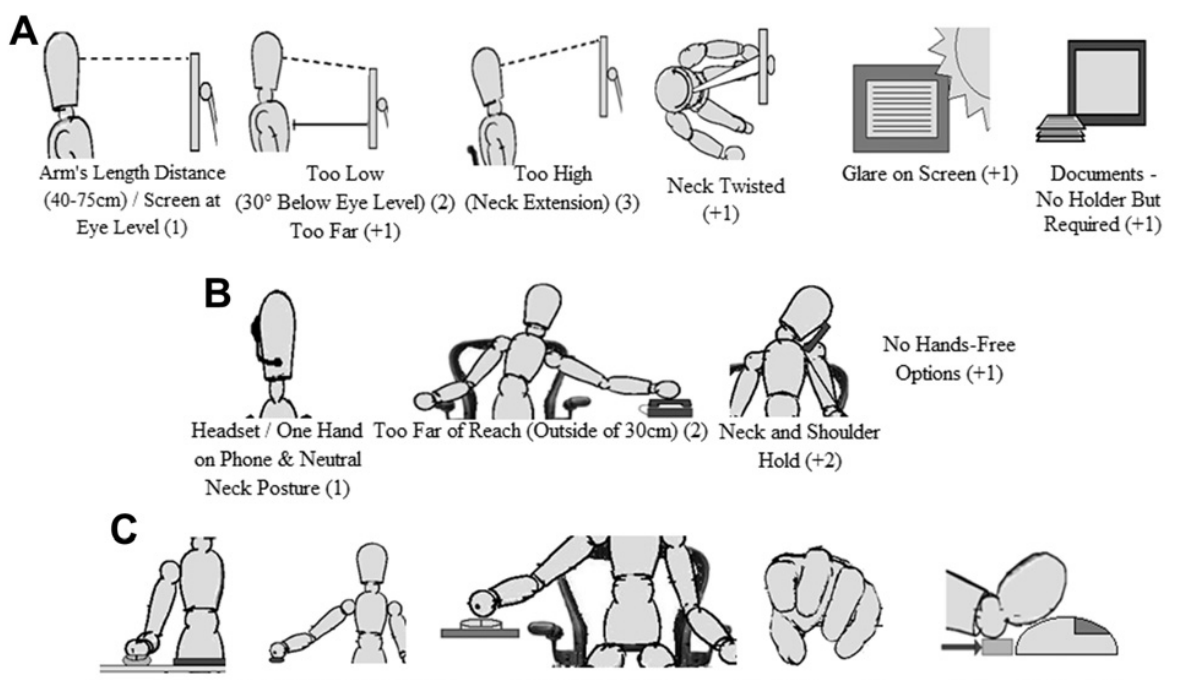

Mouse in Line with Reaching to Mouse (2)
Shoulder (1)
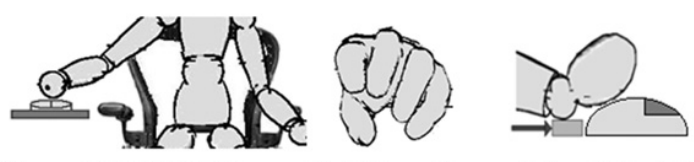

houlder (1)

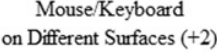

Pinch Grip on Mouse $(+1)$

Palmrest in Front of
Mouse (+1)

\section{D}
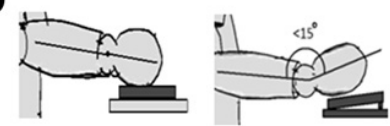

Wrists Straight, Shoulders Relaxed (1)
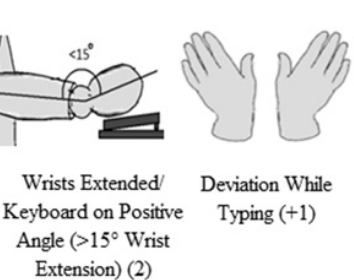

Deviation While

Typing (+1)

Extension) (2)

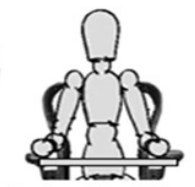

Keyboard Too High -

Shoulders Shrugged

$(+1)$

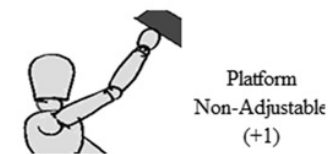

Reaching to

Overhead Items (+1)

Fig. 2. Postures and scores referring to the use of telephone, monitor and mouse [3].

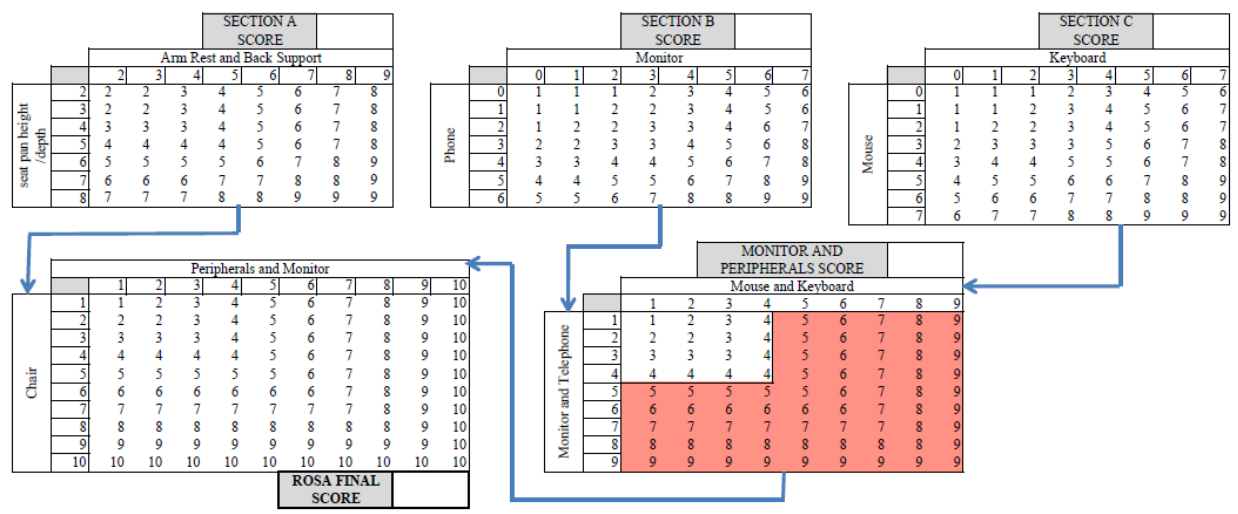

Fig. 3. Logical flow and representation of matrices used for scoring calculation - excerpt from ROSA form [3].

\section{Case study: analysis of students' learning conditions using ROSA method}

Considering that Romanian students have been learning online for a year already, understanding whether students learn in ergonomic conditions is relevant from many perspectives: the impact on students' health, efficiency of the learning process, conception of ergonomic interventions, the overall wellbeing of students. 
The authors conducted a study on students at Politehnica University of Timisoara, Romania. The study involved several stages, as follows: (1) participation in a training session on importance of office ergonomics, negative outcomes of ergonomic inadequacies and improvement solutions, (2) analysis of current conditions in which these students learn and (3) an online survey to understand the impact of online learning on students' wellbeing. Detailed description of stages and study results were provided in another paper.

As part of stage 2, students provided presentations of conditions in which they learn with details regarding anthropometric measurements, chair and desk measurements and description of the learning space. Students were invited to submit photographs of their position at the desk, as well. Based on the photographs offered by students, the authors analysed the level of compliance with ergonomic requirements. Liebregts et al. performed photograph-based ROSA assessments, proving that this approach is feasible if the assessments are performed with caution [16].

Considering applicability of ROSA method, analysing learning conditions for the above-mentioned students using ROSA method is considered relevant.

From the 120 participants invited in the first and second stages of the study, 77 participated in stage 2 of the study. However, only 53 students provided photographs suitable for analysis using ROSA method (i.e., photographs presenting the student sitting at the desk, in front of the computer/laptop and with lower part of the body and chair completely visible).

It is compulsory to make several methodological explanations: (a) typically, students do not use a telephone during their activity, hence score for telephone was 0 in all cases; (b) assessments were based only on analysis of photographs, without any physical interaction with the subjects (primarily due to pandemic restrictions), and (c) a score of 1 for duration was used across, considering that students spend more than an hour continuously in front of the screen attending online classes.

Statistical analysis of scores obtained with ROSA are presented in Table 1.

Table 1. Statistical analysis of ROSA scores.

\begin{tabular}{|c|c|c|c|c|}
\hline Indicators & $\begin{array}{c}\text { Section A } \\
\text { score }\end{array}$ & $\begin{array}{c}\text { Section B } \\
\text { score }\end{array}$ & $\begin{array}{c}\text { Section C } \\
\text { score }\end{array}$ & $\begin{array}{c}\text { Total ROSA } \\
\text { score }\end{array}$ \\
\hline Minimum & 2 & 1 & 2 & 2 \\
\hline Maximum & 8 & 3 & 5 & 8 \\
\hline Median & 3 & 2 & 3 & 4 \\
\hline Average & 3.91 & 1.96 & 2.92 & 4.19 \\
\hline Standard deviation & 1.83 & 0.43 & 0.54 & 1.60 \\
\hline $\begin{array}{c}\text { Mean confidence } \\
\text { interval (p =0.05) }\end{array}$ & 0.49 & 0.12 & 0.15 & 0.43 \\
\hline
\end{tabular}

The highest score was 8 , corresponding to a student learning in highly inappropriate ergonomic conditions: the student used an armchair and a coffee table, having a position bent forward and twisted. Also, the distance between the table and the armchair was large, generating an awkward position.

As shown in Figure 4, 21 (39.6\%) subjects had scores of 5 or more, while 32 (60.4\%) had scores below 5 . Considering that scores below 5 represent a low ergonomic risk, it is a good sign that more than half of the analysed learning spaces are safe from an ergonomic viewpoint. 
Nevertheless, the high prevalence of scores above 5 signals the ergonomic issues students are facing. From inadequate chairs (armchairs, stools, dining chairs, nonergonomic chairs), to improvised desks (coffee tables, makeup tables, dining tables, very high desks) there are students who learn in inappropriate conditions (from the ergonomic viewpoint). In addition, it is important to highlight that majority of students use laptops placed directly on the desk and do not use separately a mouse and a keyboard to improve their position at the desk. The screen of the laptop is placed well below the neutral head position, forcing students to maintain their head bent forward for prolonged periods of time and exposing them to increased risk of MSDs. At the same time, using exclusively the laptop touchpad and keyboard generate other inadequate postures that further contribute to the overall ergonomic risk.

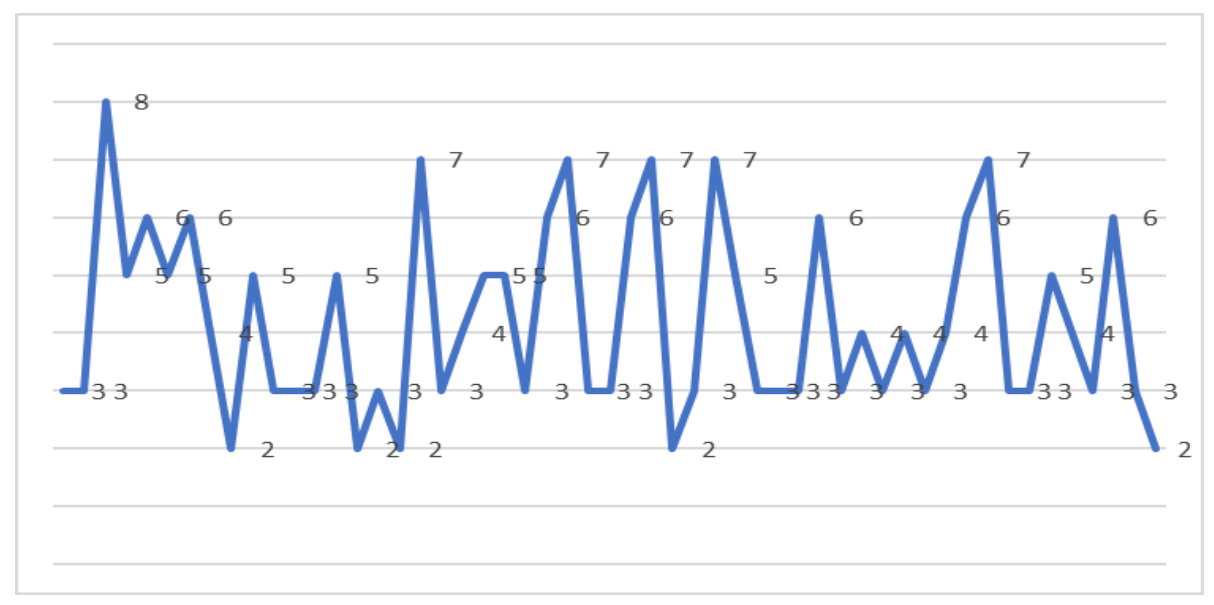

Fig. 4. Distribution of total ROSA scores for the 53 analysed learning spaces

\section{Conclusions}

Assessment of learning conditions students have at home was an ambitious attempt to understand 'behind-the-scenes' aspects of online learning. It is easily visible that many students do not have ergonomic conditions at home; some families do not afford furniture changes, while others are unaware of the negative effects of incorrect postures.

Regarding the use of ROSA, the authors consider that it is a very useful instrument due to its accessibility and simplicity. Considering that nothing made by human hands is perfect, the method has some limits, too. Not assessing a factor reduces the overall section score (in this case study, the fact that students do not use a telephone generated a smaller overall section B score). Although the factor scored 0 should not affect the overall section score, in the case of ROSA, this leads to a score reduced with 1 point. This observation highlights potential flaws in assessing many white-collar workplaces, where the telephone has been increasingly replaced with online means of communication (such as Skype, Zoom and other similar software). Another limit refers to a certain amount of subjectivity when making the assessment, as it is based solely on observation of the working system. However, subjectivity can be reduced by assigning the responsibility of the assessment to experienced ergonomists.

Results of the case study presented in this paper need to be treated with caution, as there is insufficient evidence on the possibility to generalize the output of the study. Nevertheless, the study should be expanded to the whole population of Romanian students 
to have a clear picture on the status quo of the effects and drawbacks of online learning as a long-term (or even a permanent) arrangement.

Furthermore, for the assessors (evaluators) a training program for qualification and certification of their skills and competences are needed related to the MSDs methods of study and evaluation (training should include not only ROSA method, but also other tools for evaluating the degree level of MSDs in the working systems). A good example of such approach has been presented by [17] and it has been developed and agreed in an international approach of an international consortium. The training program should be supported by university-industry collaboration [18] for the mutual benefit and for the innovativeness of the designed training program (actual, practical relevance for a group of industrial partners, ready to be implemented for industrial specialists in occupational health and safety).

\section{References}

1. V. Redivo, B. Olivier, South African J. Physiotherapy 77(1), 10 (2021)

2. Z. Jozwiak, T. Makowiec-Dabrowska, E. Gadzicka, J. Siedlecka, A. Szyjkowska, M. Kosobudzki,..., A. Bortkiewicz, Medycyna pracy, 675-700 (2019)

3. M. Sonne, D. L. Villalta, D. M. Andrews, Appl. Ergo. 43(1), 98-108 (2012)

4. F. Jusoh, M. N. O. Zahid, IOP Conf. Series: Materials Sci and Eng. 319(1), 012059, IOP Publishing (2018, March)

5. A. Umar, M. Kashif, N. Zahid, R. Sohail, A. Arsh, A. Raqib, P. Zada, Physikalische Medizin, Rehabilitationsmedizin, Kurortmedizin 29(02), 99-103 (2019)

6. S. Bagheri, M. GHaljahi, Asian Journal of Water, Environment and Pollution 16(1), 91-96 (2019)

7. A. Shariat, J. A. Cleland, M. Danaee, M. Kargarfard, V. Moradi, S. B. M. Tamrin, Iranian J. Public Health 47(11), 1756 (2018)

8. S. I. Samaei, A. Tirgar, N. Khanjani, M. Mostafaee, M. Bagheri Hosseinabadi, M. Amrollahi, H\&S at Work 5(4), 1-12 (2015)

9. M. N. A. Rahman, N. S. A. Razak, M. F. Hassan, S. Adzila, Advanced Sci. Letters 24(1), 587591 (2018)

10. E. K. Delice, G. F. Can, E. Kahya, J. Faculty of Eng. and Arch. of Gazi University 35(3), 1297$1314(2020)$

11. M. H. Safarian, F. Rahmati-Najarkolaei, A. Mortezapour, Health Scope 8(1) (2019)

12. H. Sanaeinasab, M. Saffari, F. Valipour, H. R. Alipour, M. Sepandi, F. Al Zaben, H. G. Koenig, Int. archives of occ. environ. health 91(8), 951-962 (2018)

13. K. Mani, I. Provident, E. Eckel, Work 55(4), 913-922 (2016)

14. I. Nasiri, M. Motamedzade, R. Golmohammadi, J. Faradmal, JHSW 5(2), 47-62 (2015)

15. M. Matos, P. M. Arezes, Procedia Manufacturing 3, 4689-4694 (2015)

16. J. Liebregts, M. Sonne, J. R. Potvin, App. Ergo. 52, 317-324 (2016)

17. Draghici, A., Mocan, M., Draghici, G. On-line training and certification solution for business process managers. In International Conference on ENTERprise Information Systems (pp. 380389). Springer, Berlin, Heidelberg (2011, October).

18. Draghici, A., Baban, C. F., Ivascu, L. V., Sarca, I. Key success factors for university-industry collaboration in open innovation. In 8th annual International Conference of Education, Research and Innovation, Spain, (2015, November). 